\title{
Valproinsäure verantwortlich für niedrigen IQ
}

\section{Kinder, die intrauterin Valproinsäure ausgesetzt sind, zeigen noch im 6. Lebensjahr einen signifikant reduzierten IQ im Vergleich zu Gleichaltrigen, deren Mütter Lamotrigin oder Carbamazepin einnahmen.}

— Für eine prospektive und multizentrische Studie wurden schwangere Epileptikerinnen, die Carbamazepin, Lamotrigin oder Valproat einnahmen, und ihre Kinder beobachtet. Als Kontrollgruppe dienten Schwangere mit vergleichbarem Hintergrund. Mütter mit Lernschwierigkeiten oder chronischen Erkrankungen wurden ausgeschlossen. Zum 6. Geburtstag konnten 408 von 530 Kindern untersucht werden.

Alle Kinder, deren Mütter Valproat in Dosierungen von mehr als $800 \mathrm{mg} / \mathrm{d}$ eingenommen hatten, zeigten in Tests signifikant geringere IQ-Werte (im
Durchschnitt -9,7) als Kinder, die intrauterin einem der anderen Mittel ausgesetzt waren. Auch hatten sie einen achtfach erhöhten Bedarf an Lernhilfe sowie Probleme mit räumlicher Wahrnehmung. Valproat in geringerer Dosis führte nicht zu Unterschieden beim IQ, wohl aber zu einem sechsfach erhöhten Bedarf der Lernunterstützung. Lamotrigin und Carbamazepin hatten keinen Einfluss auf den kindlichen IQ.

\footnotetext{
- Baker GA, Bromley RL, Briggs M et al.

IQ at 6 years after in utero exposure to antiepileptic drugs. A controlled cohort study. Neurology 2015;84:382-90
}

\section{Kommentar}

Die Ergebnisse sind erschreckend, wenn auch nicht mehr ganz neu. Interessant ist auch die miterfasste Tatsache, dass Kinder, deren Mütter während der Schwangerschaft eine Polytherapie benötigten, keine relevanten kognitiven Auffälligkeiten zeigten - es sei denn, dass mit Valproat kombiniert wurde. Ob Lamotrigin ganz so unschädlich ist, wie immer postuliert, bleibt auch hier offen. Grundsätzlich gilt in der Betreuung junger Frauen mit Kinderwunsch: Vorsicht mit der Verordnung und vor allem der Dosis. Was wir zwingend verinnerlichen sollten: Scheinbar gesund Geborene sollten nach Valproat-Exposition früh eine Förderung erhalten, damit kognitive Defizite, die im Alltag nicht so leicht auffallen, frühzeitig beübt werden.

Dr. med. V. Homberg -

\section{Seltene Erbkrankheit}

\section{Pseudopseudohypoparathyreoidismus}

Bei der Untersuchung eines 37-jährigen, kleinwüchsigen Mannes fiel beidseits eine Verkürzung des vierten und fünften Fingers (Abb. A) mit Fehlen der jeweiligen Knöchel (Abb. C) auf. Röntgenaufnahmen zeigten zudem eine Verkürzung der Endphalangen des 1. und 3. Fingers und der
Metacarpalia 4 und 5 (Abb. B). Diese Veränderungen sind charakteristisch für die hereditäre Albright-Osteodystrophie. Es fanden sich keine Verkalkungen im Röntgen-Thorax, Serumkalzium und Phosphat waren normal. Die normalen Spiegel des intakten Parathormons (PTH) bestätigten

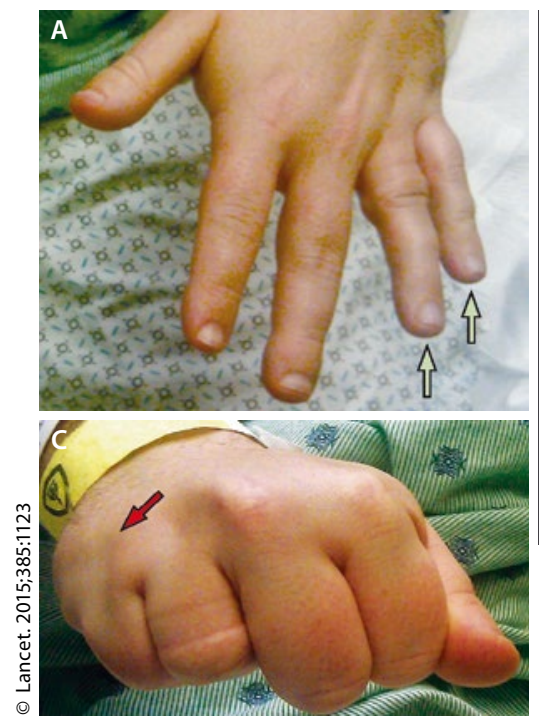

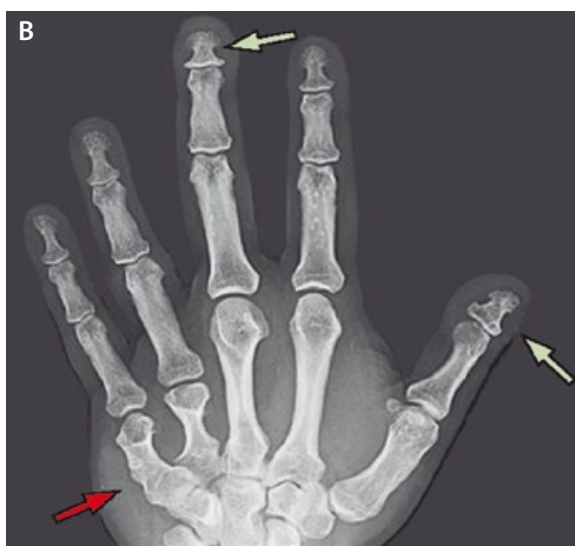

A: Verkürzung des vierten und fünften Fingers; B: fehlende Knöchel; C: verkürzte Endphalangen (weiße Pfeile) und Metacarpalia (roter Pfeil). die Diagnose eines Pseudopseudohypoparathyreoidismus.

Albright berichtete 1.942 über Patienten mit Pseudohypoparathyreoidismus, die durch Kleinwuchs, Adipositas, ein rundes Gesicht und verkürzte Metacarpalia und Metatarsalia auffielen. Eine Resistenz gegen Parathormon führte zur Hypokalzämie und Hyperphosphatämie. Später beschrieb er Patienten mit den gleichen Symptomen, aber ohne Resistenz gegen Parathormon. Diesen Zustand nannte er Pseudopseudohypoparathyreoidismus. Beiden Veränderungen liegen Mutationen der Alpha-Untereinheit des G-Proteins zu Grunde. Bei Übertragung durch die Mutter kommt ein Pseudohypoparathyreoidismus Typ 1a zustande, vom Vater erbt man einen Pseudopseudohypoparathyreoidismus. Die Anomalie erfordert keine Behandlung, allerdings wird eine genetische Beratung empfohlen.

Prof. Dr. H. S. FüeßI .

\footnotetext{
- Simpson Cet al.

(Korres.: bhousto2@jhmi.edu): Pseudopseudohypoparathyroidism. Lancet. 2015;385:1123
} 